\title{
Wireless power meter monitoring with power theft detection and intimation system using GSM and Zigbee networks
}

\author{
G. L. Prashanthi ${ }^{1,}$ K. V. Prasad ${ }^{2}$ \\ ${ }^{1}$ M.Tech, Embedded systems, VR siddhatrha institute of technology, Vijayawada, Krishna AP, India \\ ${ }^{2}$ Assistant professor, embedded systems, M.Tech, VR siddhatrha institute of technology, Krishna, AP, India
}

\begin{abstract}
With the electric industry undergoing change, increased attention is being focused on power supply reliability and power quality. Power providers and users alike are concerned about reliable power, whether the focus is on interruptions and disturbances or extended outages. Monitoring can provide information about power flow and demand and help to identify the cause of power system disturbances. The proposal in this paper is to monitor the power consumed by a model organization such a household consumers from a centrally located point. Monitoring the power means calculating the power consumed exactly by the user at a given time. The power consumed by the user is measured and communicated to the controlling substation whenever needed by the person at the substation. The feedback from the user helps in identifying usages between authorized and unauthorized users which helps in controlling the power theft, one of the major challenges in current scenarios. Communication between user/household and substation can be of wired and wireless
\end{abstract}

Keywords: Zig Bee, power theft, GSM, AT commands, wireless meter reading.

\section{Introduction}

Power theft is the biggest problem in recent days which causes lot of loss to electricity boards. In countries like India, these situations are more often, if we can prevent these thefts we can save lot of power. Electrical power theft detection system is used to detect an unauthorized tapping on distribution lines. Implementation part of this system is a distribution network of electrical power supply system. Existing system is not able to identify the exact location of tapping. This proposed system actually finds out on which electrical line there is a tapping. This is a real time system. Wireless data transmission and receiving technique is used. This will provide an additional facility of wireless meter reading with the same technique and in same cost. This will protect distribution network from power theft done by tapping, meter tampering etc.

There are two types of techniques to deliver the information to the authorized agency to control the theft of the electricity via bypassing the energy meter, those are wired and wireless. Wired networks require lot of setup and maintenance cost. In wireless technologies there are many technologies. In this project we implemented using Zigbee technology because of its effective communication, self-healing networks, low power consumption, zero traffic and they can handle over 60000 devices and more over Zigbee communication installation require no special permissions in most of the places. It uses unlicensed $2.4 \mathrm{GHz}$ ISM band which is available worldwide. ZIGBEE has range between $10 \mathrm{~m}$ to $2 \mathrm{~km}$ and it works well with networks such as Wi-Fi, Ethernet and GPRS and also provides scalable networking solution which makes it suitable to be used in controlling and monitoring application. And we selected other communication network to be GSM to send SMS to authorities in case of theft, because GSM has a built in transport layer encryption, which is supported by most network providers. GPRS offers a number of security enhancements over existing GSM security. The standards themselves also offer technical features, which a network operator may choose to use. Aside of that, a different form of security might be desired in addition to the provided transport layer security.

\section{Block Diagram}

The developed prototype consists of a transmitter tapped to meter of the consumer and a receiver at a junction place. Their respective block diagrams are as follows 


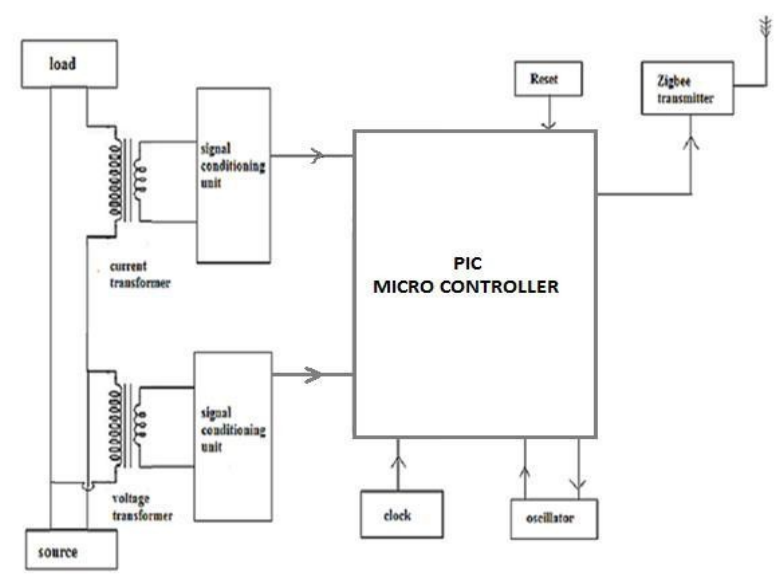

Fig: Transmitter Block diagram

It consists of Load, current transformer, voltage transformer, PIC micro controller, and a differential relay. The household load supplied is connected in series to the AC supply mains through a switch which is operated by the action of a relay. Current transformer is used to measure the current required for the user and the voltage transformer is used to measure the voltage of operation for the user. The measured values are given to the PIC micro controller which has inbuilt ADC with RISC architecture to convert the analog values to the digital values. These values are stored in microcontroller registers and the information is transmitted to the receiver, whenever there is a request for the data from the remote controlling station. Oscillator is provided to the microcontroller for the clock signal and the reference voltage is given for the each of the IC used.

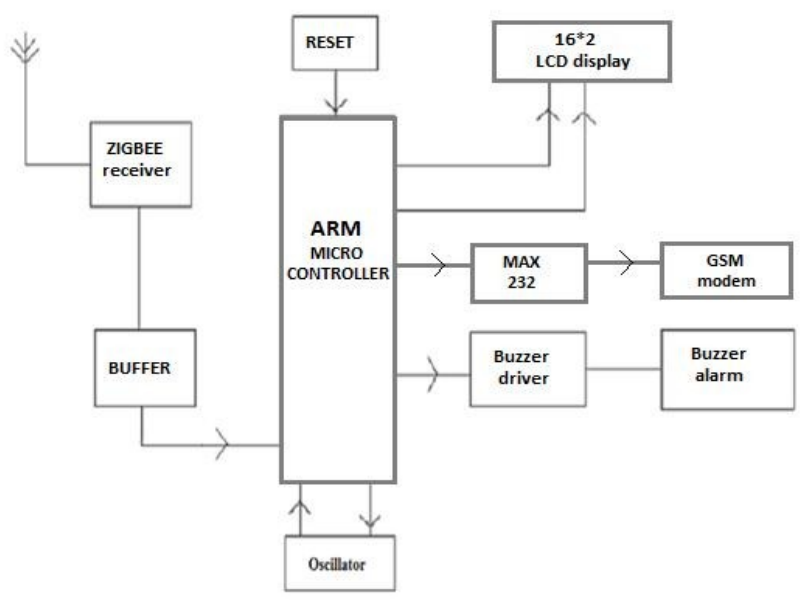

Fig: receiver block diagram

The receiver part of this prototype consists of an ARM micro controller, Zigbee receiver LCD display and alarm to pop out theft case, and also an external GSM modem to inform theft case to authorities via SMS.

\section{Automatic Meter Reading (Amr)}

Now a day utility company personnel goes at every house to take the readings of meters for billing purpose. It will create problem when consumer is out of Town or home is locked due to other reasons. This system of wireless meter reading is based on the same principle of wireless data transmission that is used in power theft detection Utility company personnel will have a device consists of wireless data receiver with microcontroller and display 


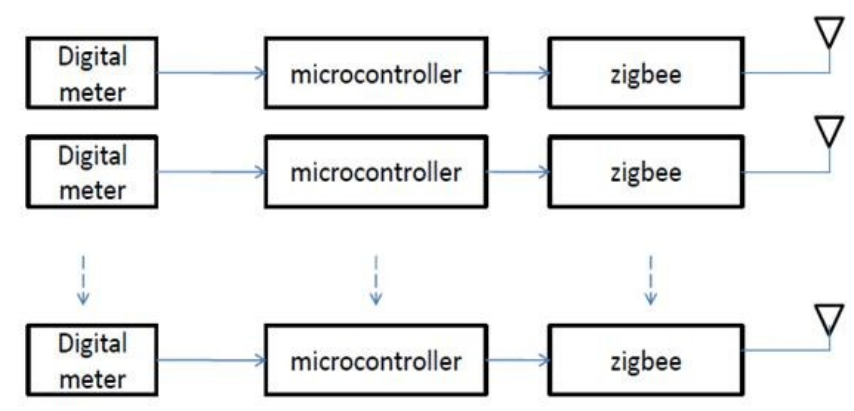

Fig: Architecture of AMR

The Base station unit will be consists of a zigbee module attached with a Transceiver micro-strip antenna, microcontroller attached to digital meter. The frequency of communication will be in $900 \mathrm{MHZ}$. the data will transmitted to the central station at regular intervals. The end station consists of an ARM micro controller receiving data from different PIC micro controllers through Zigbee receiver. The data thus received is processed and calculated the exact amount of power consumed by specific customer

\section{Power Measurement And Theft Detection}

Aim of the Remote power monitoring is to measure the exact amount of power that is consumed by the user at a given instant of time so the power measurement unit is essential and is connected on the consumer side. The power is measured by using the instrument transformers. Instrument transformers are used for measurement and protective application, together with equipment such as meters and relays. Their role in electrical systems is of primary importance as they are a means of "stepping down" the current or voltage of a system to measurable values, such as $5 \mathrm{~A}$ or $1 \mathrm{~A}$ in the case of a current transformers or $110 \mathrm{~V}$ or $100 \mathrm{~V}$ in the case of a voltage transformer. This offers the advantage that measurement and protective equipment can be standardized on a few values of current and voltage. The types of instrument transformers available are

- Voltage transformers

- Current transformers.

\section{A. Voltage transformers}

The voltage transformer is one in which "the secondary voltage is substantially proportional to the primary voltage and differs in phase from it by an angle which is approximately zero for an appropriate direction of the connections." In an "ideal" transformer, the secondary voltage vector is exactly opposite and equal to the primary voltage vector, when multiplied by the turn's ratio. In a "practical" transformer, errors are introduced because some current is drawn for the magnetization of the core and because of drops in the primary and secondary windings due to leakage reactance and winding resistance. One can thus talk of a voltage error, which is the amount by which the voltage is less than the applied primary voltage, and the phase error, which is the phase angle by which the reversed secondary voltage vector is displaced from the primary voltage vector.

\section{B. Current transformers}

A current transformer is defined as "as an instrument transformer in which the secondary current is substantially proportional to the primary current (under normal conditions of operation) and differs in phase from it by an angle which is approximately zero for an appropriate direction of the connections." This highlights the accuracy requirement of the current transformer but also important is the isolating function, which means no matter what the system voltage the secondary circuit need be insulated only for a low voltage.

The current transformer works on the principle of variable flux. In the "ideal" current transformer, secondary current would be exactly equal (when multiplied by the turn's ratio) and opposite of the primary current. But, as in the voltage transformer, some of the primary current or the primary ampere-turns are utilized for magnetizing the core, thus leaving less than the actual primary ampere turns to be "transformed" into the secondary ampere-turns. This naturally introduces an error in the transformation. The error is classified into two-the current or ratio error and the phase error.

Thus by considering all these parameters we program micro controllers to calculate the amount of power actually consumed.

\section{Theft detection method}

The simple formula behind theft detection is whenever input power is passing from supplier to the receiver, at that time if the total amount of power is not received by the receiver then there is possibility of theft 
of energy.

$$
\begin{aligned}
& \Sigma \text { Psent }=\Sigma \text { Pconsumed }+ \text { Loss } \ldots \ldots . . \text { No Theft } \Sigma \text { Psent } \neq \Sigma \text { Pconsumed }+ \text { Loss } \ldots \ldots . . \text { Theft Occur } \\
& \text { Here, } \\
& \text { Psent }=\text { Power measured by pole side energy meter Pconsumed }=\text { Power measured by load side } \\
& \text { energy meter }
\end{aligned}
$$

Consider a distribution system shown in conceptual diagram. Two single phase loads L1 and L2 are supplied from two different phases. M1 and M2 are the energy meters that measure power consumed by these loads over a period. Pole based system $(\mathrm{P})$ have been installed to detect power theft.

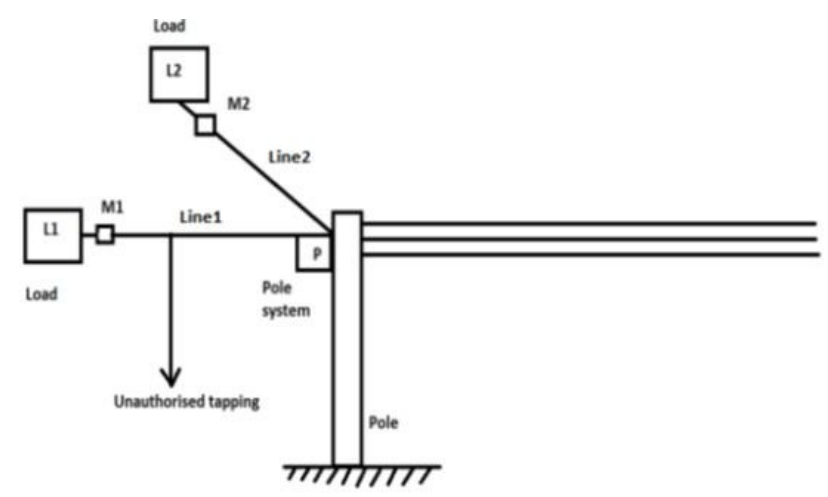

FIG2.3.1: Conceptual diagram

L1, L2 Single phase loads M1, M2 Digital energy meters

P Pole based system (installed on a distribution pole) There are three different types of systems to monitor power sent

\section{A. pole based system}

It consists of Wireless data receiver, Micro-controller, Digital energy meter. Digital energy meter will measure power sent over each line for a certain time period.

\section{B. Pole Side Energy Meter}

One energy meter is installed in a pole based system. This meter is capable to measure a power sent over each line connected to that pole.

\section{Load Side Energy Meter (M1, M2):}

Meter is installed on load side to measure a power consumed by load over a time. Also it has an additional feature of transmitting that data to receiver using wireless technique ZigBee network.

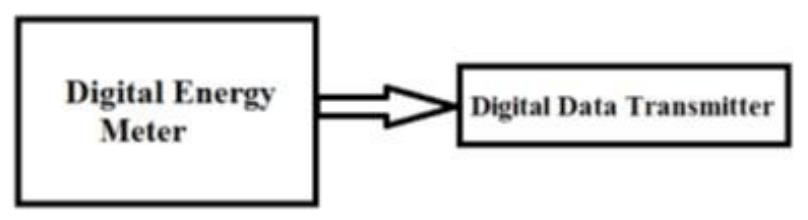

Fig: load side meter

\section{Power theft detection}

Suppose there is tapping done by any unauthorized person on the line to connect his appliance. Over a certain period there will be difference between meter reading and pole based reading.

Microcontroller will compare these two values and if the measured value on pole is more than value send by meter by some tolerance then power theft is happening on line. This theft signal generated on pole system can be transmitted to substation by power line communication technique, Tolerance should be provided for losses of line. Because over a long period there will be difference in reading of meter on load side and pole side due to loss of line between pole and load. Therefore tolerance should be provided through programming of micro-controller. 


\section{Working}

The setup is build such that every consumer is provided with an automated meter reader with inbuilt microcontroller to monitor the data consumed at regular intervals, the PIC microcontroller is employed at consumers end and Arm microcontroller is employed on pole station. PIC sends data continuously and ARM processes data, it already has the record of amount of power sent to each line and it compares this to received feedback, if the difference between these two values exceeds the prescribed limits then the ARM microcontroller understands that power theft was happened and raises an alarm, also sends this information to local authorities via GSM modem

There is a prescribed limit because, we have to keep track of all general power losses other than theft and PIC was employed at consumers end, while ARM at pole station. This is because both has inbuilt ADC and RISC architecture but PIC is 8-bit and cheaper it serves the purpose perfectly, while on pole station ARM receives data from various PIC's and need higher RAM and architecture to process data quickly, so ARM with 32-bit architecture is employed.

\section{Conclusion}

The progress in technology about electrical distribution network is a non-stop process. New things and new technology are being invented. The proposed system found to be little bit complex as far as distribution network is concerned, but it's an automated system of theft detection. It saves time as well as help to maximize profit margin for utility company working in electrical distribution network. Utility company can keep a constant eye on its costumer. And the extension of this project with GSM modules helps company to monitor the amount of usage by the specified customer and generate bill periodically and send it to customer via SMS, thus saving lot of labor work, time and cost of reading.

\section{Journal Papers}

\section{References}

[1] C. Jägerlind, "Improvements for the automatic meter reading process in electricity distribution companies," Master Thesis, Dep. Industrial Info and Control Systems, Royal Institute of Technology, Stockholm, Sweden 2006.

[2] A. Abdollahi, M. Dehghani, and N. Zamanzadeh , "SMS-based reconfigurable automatic meter reading system," IEEE International Conference on Control Applications (CCA 2007), Oct, 2007, pp. 1103 - 1107.

[3] C. Brasek, "Urban utilities warm up to the idea of wireless meter reading," The IEE Computing and Control

[4] C. Nunn, P. Moore, \& P. Williams "Remote meter reading and control using high- performance plc communication over the low voltage and medium voltage distribution networks," in 7th International Conference on Metering Apparatus and Tariffs for Electricity Supply, 1992, pp. 304-308.

[5] international Conference and Exhibition on Electricity Distribution, Prague, Czech Republic, June 2009, pp. 1-4

Books

[6] V.K.Mehta and Rohit Mehta, "Principles of Power System", 4 th ed, S. Chand publication, 2008.

Thesis

[7] M.A.O liveira and C.C. Barioni, "Technical loss calculation by distribution system segment with corrections from measurements", Proc.20th

[8] J. Tsoi, "Device management of largescale amr systems," MSc thesis, Dep. of Industrial Information and Control Systems, Royal Institute of Technology in Stockholm (KTH), Stockholm, Sweden 2006. 